\title{
Calculated estimation of railway wheels equivalent conicity influence on critical speed of railway passenger car
}

\author{
Juraj Gerlici ${ }^{1, *}$, Rostyslav Domin ${ }^{2}$, Ganna Cherniak $^{2}$, Tomáš Lack ${ }^{1}$ \\ ${ }^{1}$ University of Žilina, Faculty of Mechanical Engineering, Department of Transport and Handling \\ Machines, 01026 Žilina, Slovak Republic \\ ${ }^{2}$ Volodymyr Dahl East Ukrainian National University, Department of Rail Transport, 93400 \\ Sewerodonetsk, Ukraine
}

\begin{abstract}
The article presents the results of determining the equivalent conicity characterizing the geometric interaction of wheels and rails on $1520 \mathrm{~mm}$ track. The cases of interactions of rails and wheelsets, wheels of which have different profiles, are considered. The computer model of the motion speed of the passenger car is developed. According to the results of computer simulation, critical speeds for the bogie moving through the tracks of indented gauge are received. Based on the results of the simulation analysis, the significant dependence of the value of the equivalent conicity on the critical speed is confirmed. The necessity of considering the limit values of equivalent conicity in tests of high-speed rolling stock is emphasized.
\end{abstract}

Keywords: railway wheels, equivalent conicity, critical speed, passenger vehicle

\section{Introduction}

The increase of speed of passenger trains up to $160-200 \mathrm{~km} / \mathrm{h}$ brings new technological level on the Ukrainian railways. Cars of high-speed trains must fully comply with international requirements, both in the level of comfort, and in terms of safety. In this regard, the task of ensuring the stability of motion of the high-speed rolling stock must be resolved as a matter of priority. According to the results of numerous researches, depending on the design and parameters of running gears the configuration of working surfaces of wheels and rails significantly affects the dynamic behavior of rail vehicles, in particular, critical speeds in respect of hunting oscillations $[1,4,6]$. The problem of optimal interaction of underframes and the track becomes of particular importance for high-speed rolling stock.

According to regulatory documents operating on the railways of the European Union, field tests on the admission of the rolling stock to operation must be carried out under certain parameters of interaction between wheels and rails, including those which reflect the conditions of the worn out surfaces in contact $[5,13]$. Such an approach was implemented to test the impact of natural wear of wheels and rails on the dynamic characteristics of the

* Corresponding author: juraj.gerlici@fstroj.uniza.sk

Reviewers: Alžbeta Sapietová, Josef Soukup 
rolling stock. The results of the relevant research proved that for certain units of the rolling stock critical speeds in respect of hunting oscillation are considerably sensitive to contours of the threads of wheels [3]. However, up to this day regulatory documents on running dynamic tests of rolling stocks for $1520 \mathrm{~mm}$ tracks do not envisage tests on the impact of the depreciation of wheels on the dynamic behavior of the rolling stock, which does not allow qualitatively assess of its running characteristics in real operating conditions [2].

\section{Characteristics of equivalent conicity}

According to numerous studies of oscillations and stability of motion of railway rolling stocks, geometric characteristics of the interaction of wheels and rails are the factors that determine the dynamic properties of the rolling stock $[8,11]$. Therefore, in the study of conditions for safe and comfortable operation of the rolling stock intended for operation with high speeds, the impact of geometric characteristics of the interaction of wheels and rails should be estimated as a matter of priority.

Among the parameters that characterize the geometric interaction of wheelsets and rails, the so-called "equivalent conicity" takes on the generalized role. Namely this parameter provides optimal estimation of the contact of the pair "wheel-rail" on straight sections of track and in curves of large radius. According to the known definitions, the equivalent conicity is equal to tangent $\operatorname{tg} \gamma_{e}$ of the cone angle $\gamma_{e}$ of the wheelset with conical wheels, transverse movement of which has the same kinematic wavelength as this wheelset [12].

The equivalent conicity provides an opportunity to compare conditions of the contact of wheels and rails in different states based on the design and maintenance. The linearization approach is used. This approach involves the replacement of nonlinear dependence of the change of the radius of rolling circumference for linear one. The angular coefficient of linear dependence is the equivalent conicity.

It is necessary to adhere to common rules in determining the equivalent conicity in order to able to compare the results obtained for various railways. For this purpose, the International Union of Railways implemented the principles of calculating the equivalent conicity defined by UIC 519 Leaflet [12].

Methods of calculating the equivalent conicity are as follows: analytical description of profiles of wheels and rails is given; $\Delta r=f(y)$ characteristic is calculated for each lateral displacement $y$ of the wheelset as the difference between right and left radius of rolling circumference of wheels $\Delta r=r_{r}-r_{l}$; the equivalent conicity $\operatorname{tg} \gamma_{e}$ for the lateral displacement $y$ of the wheelset is determined using linear regression for the part of $\Delta r=f(y)$ characteristic within $2 y$ interval.

The equivalent conicity should be calculated with the actual wheel profile of the tested vehicle and theoretical profile of the rail of the track with corresponding gauge. The lateral displacement of the wheelset is considered in the range of $y= \pm 3 \mathrm{~mm}$.

Acceptable values of the equivalent conicity, which should not be exceeded during the test of the rolling stock on the track, depend on the speed characteristics of rolling stocks and equal to [5]: 0.5 - at $V \leq 140 \mathrm{~km} / \mathrm{h} ; 0.4-140 \mathrm{~km} / \mathrm{h}<V \leq 200 \mathrm{~km} / \mathrm{h} ; 0.35-200 \mathrm{~km} / \mathrm{h}<V \leq$ $230 \mathrm{~km} / \mathrm{h} ; 0.3-230 \mathrm{~km} / \mathrm{h}<V \leq 250 \mathrm{~km} / \mathrm{h} ; 0.25-250 \mathrm{~km} / \mathrm{h}<V \leq 280 \mathrm{~km} / \mathrm{h} ; 0.15-280$ $\mathrm{km} / \mathrm{h}<V \leq 350 \mathrm{~km} / \mathrm{h}$.

Values of the equivalent conicity for options of wheels profiles used on the Ukrainian railways are calculated in accordance with the said method, in particular, with GOST 9036 and DMetI, developed at the National Metallurgical Academy (Dnipro city) [7]. The wheel profile complying with GOST 9036 is considered in two states: initial (new or turned) and worn (Fig. 1). 


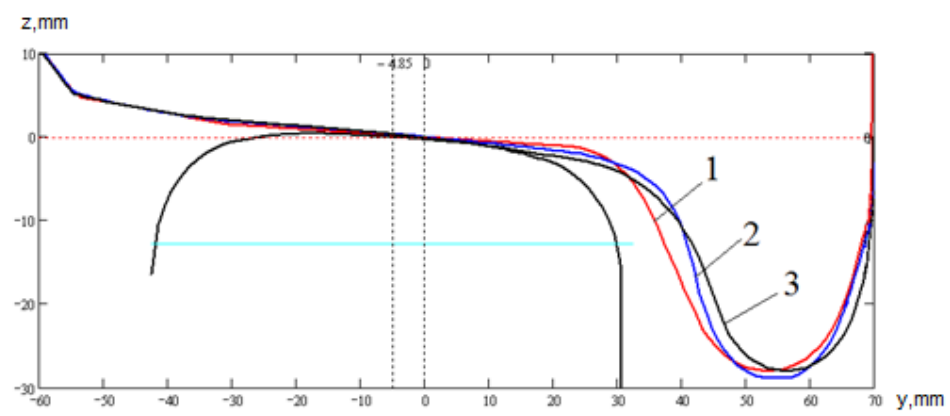

Fig. 1. Profiles of considered wheels

( 1 - new profile complying with GOST; 2 - profile with wear; 3 - DMetI profile)

According to the recommendations of the Organization for Railways Cooperation, at the maintenance of track on the sections of high-speed operation minimum gauge tolerances are $(+2,-2)$, and the maximum ones are $(+6,-4)$ [9]. Thus, the gauge for $1520 \mathrm{~mm}$ track may be within $1516-1526 \mathrm{~mm}$ range. Equivalent conicities at the change of gauge of the track with P65 rails within the specified range in increments of $2 \mathrm{~mm}$ are calculated for given profiles of wheels.

The results of calculations showed that equivalent conicity $\operatorname{tg} \gamma_{e}$ for wheels with new standard profile of the running surface within the gauge changes from 1516 to $1526 \mathrm{~mm}$ is constant and equals to 0.05 . The equivalent conicity for wheels with worn running surface changes from the value of 0.247 at $1516 \mathrm{~mm}$ track to the value of 0.111 at $1526 \mathrm{~mm}$ track. When the track gauge varies from $1516 \mathrm{~mm}$ to $1520 \mathrm{~mm}$, the value of $\operatorname{tg} \gamma_{e}$ varies from 0.247 to 0.142 . When the track gauge amounts to $1522 \mathrm{~mm}, \operatorname{tg} \gamma_{e}$ is equal to 0.149 , and when the track gauge increases from $1524 \mathrm{~mm}$ to $1526 \mathrm{~mm}$, the value of the equivalent conicity changes from 0.133 to 0.111 .

For the wheel with the running surface complying with DMetI profile the value of the equivalent conicity gradually changes from $\operatorname{tg} \gamma_{e}=0.128$ at $1516 \mathrm{~mm}$ track gauge to $\operatorname{tg} \gamma_{e}=$ 0.115 at $1526 \mathrm{~mm}$ track gauge, which more than double the value of effective conicity in case of wheels with the standard profile of running surfaces.

Differences between the values of effective conicity for wheels with different profiles lead to a change in lengths of hunting waves $L_{h e}$ of the wheelset. Thus, in the case of wheels turned in accordance with GOST 9036 profile $L_{h e}$ is equal to $17.21 \mathrm{~m}$ and independent of the track gauge, and in case of worn wheels the value of $L_{h e}$ varies from $7.74 \mathrm{~m}$ at $S=1516$ $\mathrm{mm}$ to 11.55 at $S=1526 \mathrm{~mm}$. In case of the use of DMetI profile the length of the hunting wave of the wheelset slightly varies from $10.76 \mathrm{~m}$ to $11.35 \mathrm{~m}$ at the increase of track gauge within $1516-1526 \mathrm{~mm}$ range.

It should be noted that the reduction in the length of the hunting wave increases frequencies of horizontal oscillations of the rolling stock. Thus, at $\mathrm{V}=160 \mathrm{~km} / \mathrm{h}$ the frequency of hunting oscillations of the wheelset with GOST 9036 profile wheels at 1520 $\mathrm{mm}$ track is $2.60 \mathrm{~Hz}$, whereas the frequency of hunting oscillations of the wheelset with worn wheels increases to $4.35 \mathrm{~Hz}$.

Table 1 brings together the values of effective conicity $\operatorname{tg} \gamma_{e}$ and the length of the hunting wave $L_{h e}$, which are calculated for three configuration options of wheels running surfaces in question at different track gauges.

Table data showed that considered combinations of wheels profiles and rails differ significantly by the nature of interaction. According to the results of numerous studies, configuration of working surfaces of wheels and rails can significantly affect the dynamic behavior of rail vehicles, in particular, critical speeds in respect of hunting oscillations depending on the design and parameters of the running gears. 
Table 1. The length of hunting waves at the interaction of wheelsets with wheels with different profiles and railway track

\begin{tabular}{|c|c|c|c|c|c|c|}
\hline \multirow{2}{*}{$\begin{array}{c}\text { Track gauge, } \\
\mathbf{m m}\end{array}$} & \multicolumn{4}{|c|}{ Standard profile } & \multicolumn{2}{c|}{ DMetI profile } \\
\cline { 2 - 7 } & \multicolumn{2}{|c|}{ New } & \multicolumn{2}{c|}{ Worn } & \multicolumn{2}{c|}{} \\
\cline { 2 - 6 } & $\boldsymbol{t g} \boldsymbol{\gamma}_{\boldsymbol{e}}$ & $\boldsymbol{L}_{\boldsymbol{h} \boldsymbol{e}}, \mathbf{m}$ & $\boldsymbol{t} \boldsymbol{g} \boldsymbol{\gamma}_{\boldsymbol{e}}$ & $\boldsymbol{L}_{\boldsymbol{h} \boldsymbol{e}}, \mathbf{m}$ & $\boldsymbol{t} \boldsymbol{\gamma}_{\boldsymbol{e}}$ & $\boldsymbol{L}_{\boldsymbol{h} \boldsymbol{e}}, \mathbf{m}$ \\
\hline 1516 & 0.05 & 17.21 & 0.247 & 7.74 & 0.128 & 10.76 \\
\hline 1518 & 0.05 & 17.21 & 0.177 & 9.15 & 0.126 & 10.84 \\
\hline 1520 & 0.05 & 17.21 & 0.142 & 10.21 & 0.123 & 10.98 \\
\hline 1522 & 0.05 & 17.21 & 0.149 & 9.97 & 0.12 & 11.11 \\
\hline 1524 & 0.05 & 17.21 & 0.133 & 10.55 & 0.117 & 11.25 \\
\hline 1526 & 0.05 & 17.21 & 0.111 & 11.55 & 0.115 & 11.35 \\
\hline
\end{tabular}

\section{Determination of critical speeds}

Critical speeds depending on the equivalent conicity were determined for passenger car. For this purpose, the basic computer model of spatial dynamics of high-speed passenger car was used $[1,3]$.

The mathematical model of passenger car was made in UM package in accordance with subsystems method [10]. Structurally "Passenger car" object is an integral system consisting of individual subsystems of solid bodies interconnected by articulations and load-bearing elements. Accepted subsystems of the car are body and bogies, which in turn include wheelsets subsystems. Therefore, model of the system has three levels (Fig. 2): 1 "Wheelsets"; 2 - "Bogie"; 3 - "Passenger car". The general model contains identical subsystems with equivalent identifiers of parameters of inertial characteristics of bodies, elastic-dissipative properties and force relations. The general system "Passenger car" composed of 19 solid bodies, 18 linear and 22 bipolar load-bearing elements.

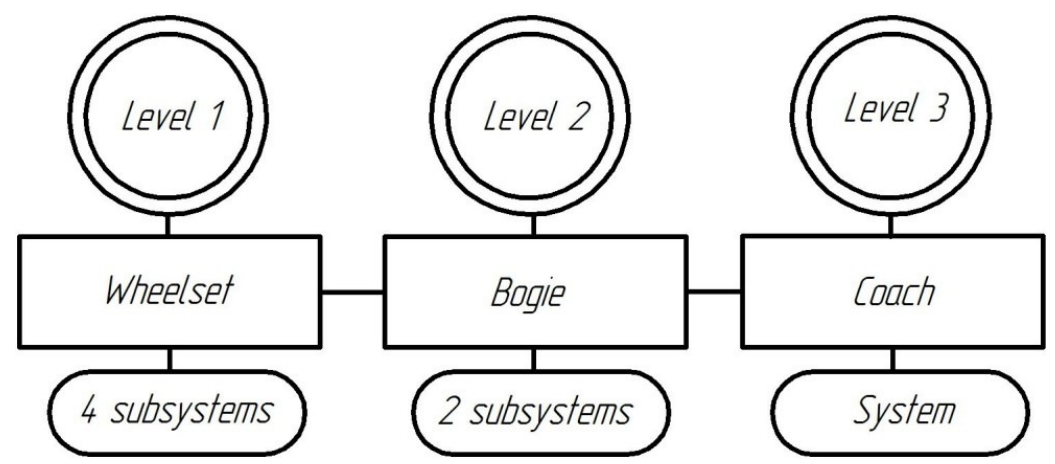

Fig. 2. Structural flow-chart of model development for car dynamics

The computer model of the rolling stock in question was supplemented with appropriate components in order to study the impact of oscillation dampers, in particular, hunting dampers, on the dynamics of the rolling stock (Fig. 3).

The simulation of running of the car through the track without destabilizations with continuous reduction of speed from maximum to the set one was carried out. The speed range of $140-50 \mathrm{~m} / \mathrm{s}$ was considered in calculations. The rate of speed drop was $4.2 \mathrm{~m} / \mathrm{s} / \mathrm{s}$ at the specified integration time for motion equations $-30 \mathrm{~s}$. Time based historical graphs 
for lateral displacements of wheelsets were made for each calculation option. At that, the critical speed $V_{c}$ was determined by the moment when self-oscillation regime stopped.

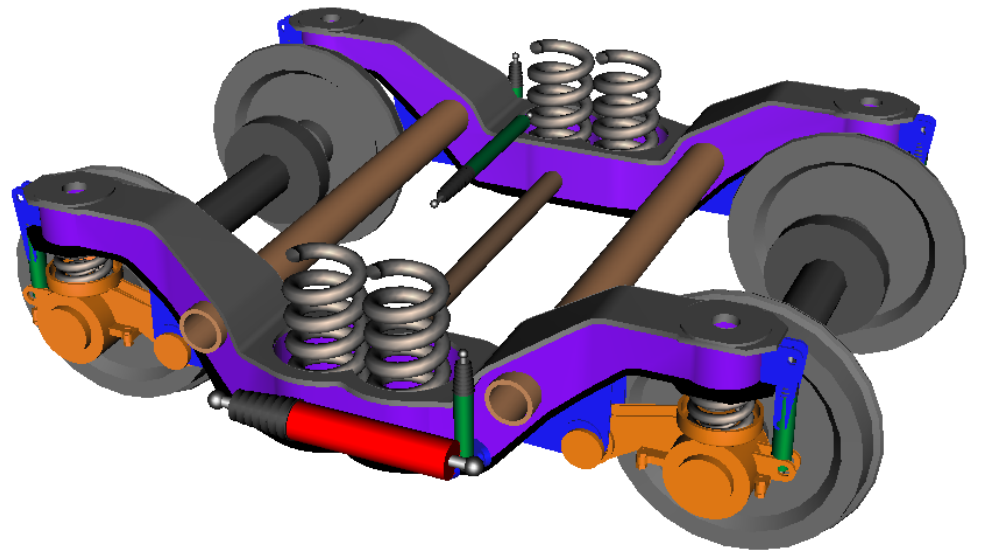

Fig. 3. Graphic representation of the model of bogie with oscillation dampers

Fig. 4 shows consolidated time based historical graphs for lateral displacements of all four wheelsets with wheels in the initial (new) state on $1520 \mathrm{~mm}$ track. As seen from the figure, in this case self-oscillations of wheelsets die out for 12 seconds, and at the given rate of motion speed drop this corresponds to the value of $89.4 \mathrm{~m} / \mathrm{s}$, i.e. $V_{c}=89,4 \mathrm{~m} / \mathrm{s}$. The results of calculations in case of new wheels turned in accordance with GOST 9036 profile, at other values of track gauge within the range of $1512-1526 \mathrm{~mm}$, showed the insensitivity of the critical speed in respect of hunting oscillations to track gauge changes.

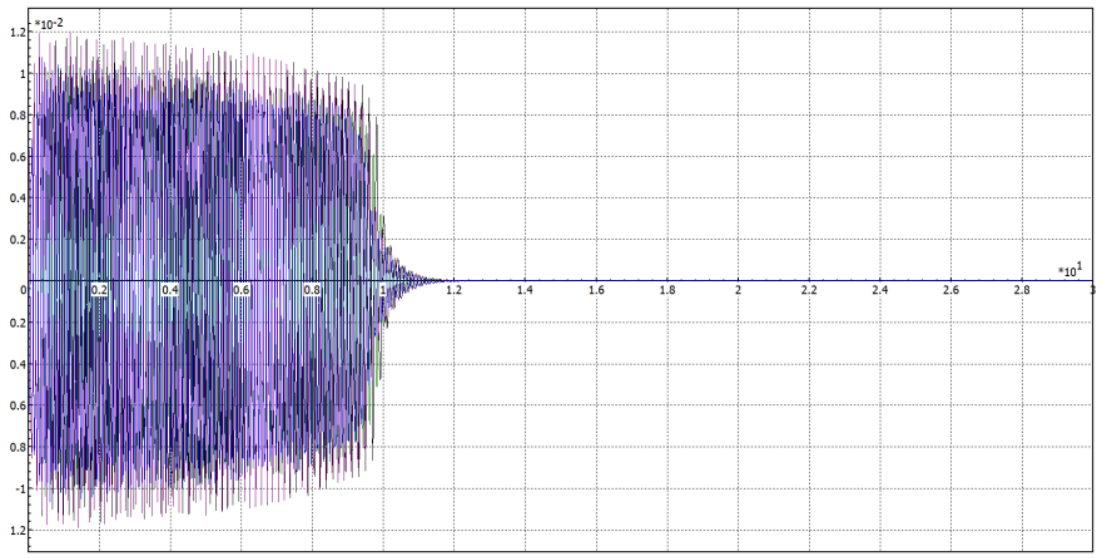

Fig. 4. Horizontal lateral displacement of wheelsets (wheel profile in accordance with GOST 9036). Horizontal axis: time [s], Vertical axis: wheelset lateral displacement [m]

Graphs for displacement of wheelsets with worn wheels at $1520 \mathrm{~mm}$ track are shown in Fig. 5. In this case critical speed is $48.3 \mathrm{~m} / \mathrm{s}$. The comparison of this data and data from the Fig. 4 showed that parameters of motion stability of the car when moving through the track with nominal gauge are severely affected by wheels wear. At the same time there is the following upward trend in increases in critical speeds with an increase at the track gauge: at $S=1516 \mathrm{~mm}-V_{c}=5.4 \mathrm{~m} / \mathrm{s}$; at $S=1518 \mathrm{~mm}-V_{c}=30.7 \mathrm{~m} / \mathrm{s} ;$ at $S=1520 \mathrm{~mm}-V_{c}=48.3$ $\mathrm{m} / \mathrm{s}$; at $S=1522 \mathrm{~mm}-V_{c}=64.4 \mathrm{~m} / \mathrm{s}$; at $S=1524 \mathrm{~mm}-V_{c}=77.1 \mathrm{~m} / \mathrm{s}$; at $S=1526 \mathrm{~mm}-V_{c}$ $=88.3 \mathrm{~m} / \mathrm{s}$. 


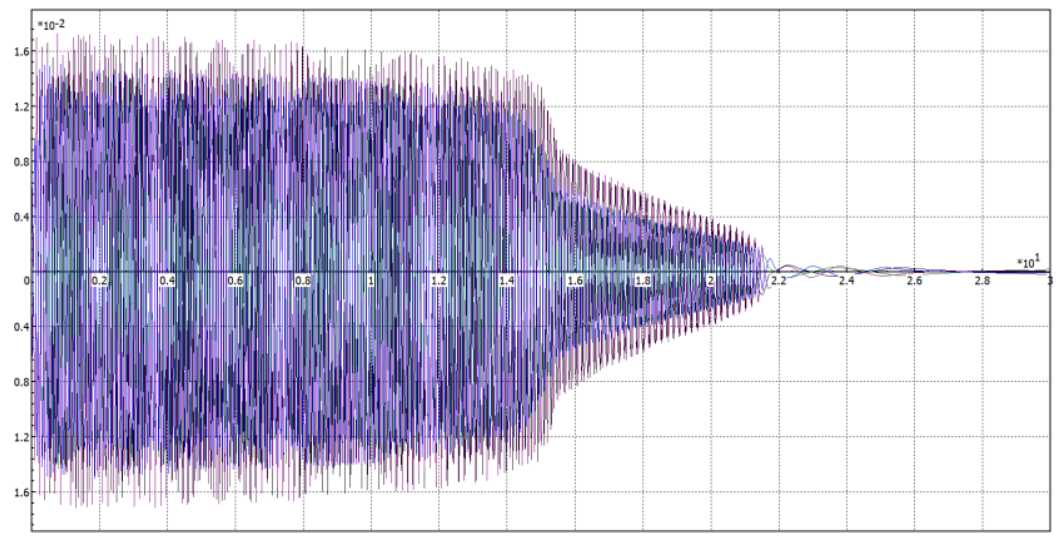

Fig. 5. Horizontal lateral displacement of wheelsets (wheels with wear). Horizontal axis: time [s], Vertical axis: wheelset lateral displacement [m]

Fig. 6 shows graphs for lateral displacements of wheelsets with DMetI profile wheels at $1520 \mathrm{~mm}$ track. According to the results of computer simulations in this calculation case, there is a conclusion on low sensitivity of critical speed to track gauge changes. Thus, when the track gauge is within the range of $\mathrm{S}=1516-1522 \mathrm{~mm} V_{c}$ is equal to $56.0 \mathrm{~m} / \mathrm{s}$, and when the track gauge is within the range of $\mathrm{S}=1524-1526 \mathrm{~mm} V_{c}$ is equal to $60.1 \mathrm{~m} / \mathrm{s}$.

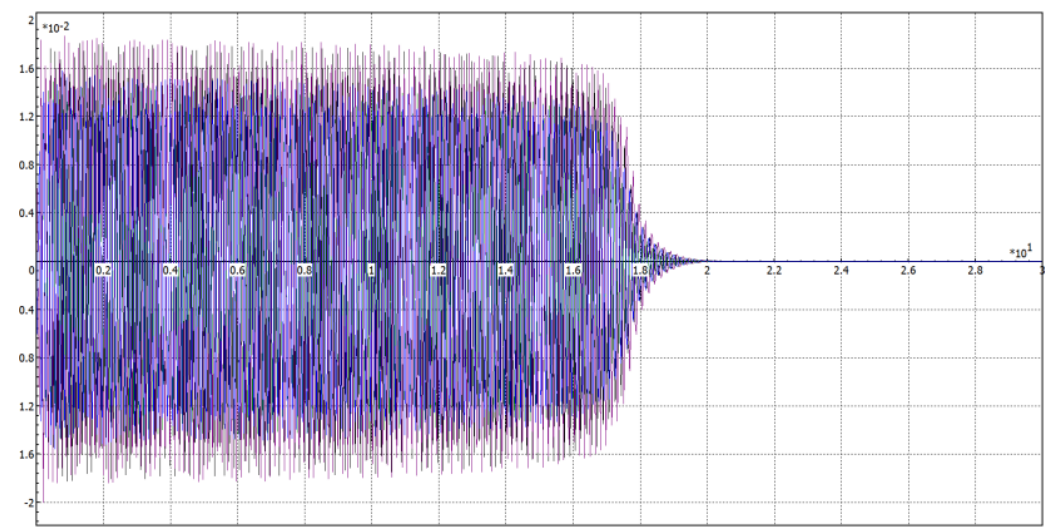

Fig. 6. Horizontal lateral displacement of wheelsets (DMetI wheel profile). Horizontal axis: time [s], Vertical axis: wheelset lateral displacement [m]

Since the problem of the loss of stability of motion is still relevant for the rolling stock with design speeds of $160 \mathrm{~km} / \mathrm{h}$ and higher, hunting dampers are widely used as effective means of suppression of self-induced oscillations of railway rolling stocks. The impact of these dampers on the dynamics of high-speed car was studied in this work. According to the results of corresponding calculations, critical speeds generally increase when implementing hunting dampers. The value of the increase in critical speeds depends on the used wheel profile. 


\section{Conclusion}

The value of equivalent conicity characterizing the geometric interaction of wheels and rails was calculated according to the said method for wheel profiles that are used on 1520 $\mathrm{mm}$ track railways. The impact of equivalent conicity on the length of the hunting wave and on critical speeds in terms of hunting self-oscillations depending on the track gauge was studied. The results of the study also confirmed the significant dependence of critical speeds on operation of hunting dampers in bogies. The value of the increase in critical speeds depends on the used wheel profile. Based on the results of studies it is recommended to include running dynamic tests in the development of regulatory documents on the admission to operation of the rolling stock for $1520 \mathrm{~mm}$ track with design speeds of 160 $\mathrm{km} / \mathrm{h}$ and higher, taking into account the limit values of equivalent conicity.

\section{References}

1. Y. Diomin, Stabilization of high-speed railway vehicles. Vehicle System Dynamics Int. J. of Vehicle Mechanics and Mobility 23 (1), 107-114 (1994)

2. Y. Diomin, R. Diomin, Procedural issues acceptance of rolling stock gauge 1435/1520 mm. Prace naukowe Politechniki Warszawskiej. Transport 98, 119-124 (2013)

3. Y. Diomin, L. Dlugach, M. Korotenko, O. Markova, Self-oscillations and motion stability of rail vehicles. [in Russian], Kyiv, Naukova dumka 160 (1984)

4. J. Elkins, A. Carter, Testing and analysis techniques for safety assesment of rail vechicles: The State-of-the-Art. Vehicle System Dynamics Int. J. of Vehicle Mechanics and Mobility 22, 185-208 (1993)

5. EN 1436, Railway applications - Testing for the acceptance of running characteristics of railway vehicles - Testing of running behaviour and stationary tests. (2005)

6. S. Iwnicki, Handbook of Railway Vehicle Dynamics. (CRC Press, 535 p., 2006)

7. V. Kulieshov, A. Sladkovsky, On the effectiveness of the work on the "wheel-rail" program in the locomotive sector of Ukraine. [in Russian] Railway Transport of Ukraine 3, 22-24 (2001)

8. T. Lack, J. Gerlici, Delta $r$ negative shape influence on the equivalent conicity assessment manner. [in Slovak] Computational and experimental methods in applied mechanics I, 27-36 (2013)

9. OSJD, Regulation on the laying and maintenance of the track on railway sections for high-speed operation (speed up to $200 \mathrm{~km} / \mathrm{h}$ inclusively). OSJD Code 788 (2011)

10. D. Pogorelov, Simulation of Rail Vehicle Dynamics with Universal Mechanism Software. Rail vehicle dynamics and associated problems, 13-58 (2005)

11. O. Polach, Influence of wheel/rail contact geometry on the behaviour of a railway vehicle at stability limit. ENOC-2005, 2203-2210 (2005)

12. UIC Code 519, Method for determining the equivalent conicity. International Union of Railways (2004)

13. UIC Code 518, Testing and approval of railway vehicles from the point of view of their dynamic behaviour - Safety - Track fatigue - Ride quality. International Union of Railways (2009)

14. A. Sapietová, M. Sága, P. Novák, R. Bednár, J. Dižo, Design and application of multisoftware platform for solving of mechanical multi-body system problems. Mechatronics: Recent technological and scientific advances, 345-354 (2011) 